\title{
Perlindungan Hak Anak Korban Tindak Pidana
}

\section{Winda Gadis Sukardi ${ }^{1 *}$, Leviana Rachel ${ }^{2}$, Putri Nadia ${ }^{3}$}

\author{
${ }^{123}$ Fakultas Hukum Tarumanagara, Jakarta \\ windagadis88@gmail.com ${ }^{1}$, levianauntar60030@gmail.com ${ }^{2}$, \\ putrinadianuru13007@gmail.com ${ }^{3}$ \\ * Corespondence Author
}

\begin{abstract}
Abstrak
Hak hidup adalah hak yang secara langsung diberikan Tuhan kepada manusia, semua mahkluk hidup berhak memiliki itu demikian pada anak keberadaan anak di Indonesia diatur tegas dalam Undang-Undang dan dalam Hak Asasi Manusia sehingga anak memiliki hak yang sama dengan orang dewasa. Zaman semakin modern sehingga keberadaan anak selalu disepelekan seperti dalam kasus seorang Ibu membunuh anak kandungnya tindakan ini yang dapat merusak kehidupan, tahap tumbuh kembang, dan kebahagian anak-anak. Keberadaan penegakan hukum terhadap pelaku kejahatan pada anak sangat diperlukan guna menjamin tumbuh kembang anak secara wajar dalam lingkungan yang sehat dan harmonis dan saksi tegas agar pelaku jera. Metode yang digunakan penulis dalam penyusunan artikel ilmiah ini adalah penelitian hukum normatif. menggunakan teknik pengumpulan data dan pengolahan data dilakukan secara kualitatif selanjutnya dianalisis menggunakan metode deduktif artinya menarik kesimpulan yang bersifat khusus dari pernyataan-pernyataan yang sifatnya umum.
\end{abstract}

\section{Kata kunci : Perlindungan, Hak, Anak}

Naskah dikirim: 17 Juli 2020|Direvisi : 10 Agustus 2020|Diterbitkan: 31 Agustus 2020 


\begin{abstract}
The right to life is a right that is directly given by God to humans, all living things have the right to have it. In children, the existence of children in Indonesia is strictly regulated in Law and in Human Rights so that children have the same rights as adults. The era is getting more modern so that the existence of a child is always underestimated, as in the case of a mother killing her biological child, this action can damage the life, stage of development, and happiness of the children. The existence of law enforcement against perpetrators of crimes against children is very necessary to ensure the normal growth of children in a healthy and harmonious environment and a firm witness so that the perpetrators are deterred. The method used by the author in the preparation of this scientific article is normative legal research. using data collection techniques and data processing is done qualitatively then analyzed using the deductive method which means drawing specific conclusions from general statements.
\end{abstract}

\title{
Keywords: Protection, Rights, Children
}

\section{Pendahuluan}

Menurut Undang-undang Nomor 39 tahun 1999 Hak Asasi Manusia hak asasi manusia yaitus eperangkat hak yang melekat pada hakikat dan keberadaan manusia sebagai makhluk Tuhan Yang Maha Esa dan merupakan anugerah-Nya yang wajib dihormati, dijunjung tinggi dan dilindungi oleh negara, hukum dan Pemerintah. Sama halnya pada anak yang mempunyai Hak tanpa diskriminasi ras, warna kuit, jenis kelamin, bahasa, agama, pendapat politik, atau pendapat lainnya ${ }^{1}$, dalam UndangUndang Perlindungan Anak diatur bahwa "Setiap anak selama dalam pengasuhan orang tua, wali, atau pihak lain mana pun yang bertanggung jawab atas pengasuhan berhak mendapat perlindungan dari perlakuan diskriminasi eksploitasi, baik ekonomi maupun seksual penelantaran, kekejaman, kekerasan, dan penganiayaan ketidakadilan

${ }^{1}$ Gunakaya,Widiada. (2017) Hukum Hak Asasi Manusia. Yogyakarta: Andi Jogja, hal 13

DOI: https://doi.org/10.30598/belovol6issue1page89-100 
dan perlakuan salah lainnya"2. Seorang ahli Jean Jacques Rousseeal J (1712-1778 M) dalam bukunya $\mathrm{Du}$ Contract social menjelaskan bahwa sebenarnya manusia itu dilahirkan merdeka dan berhak untuk rnelaksanakan kemerdekaannya di dalam batas yang telah ditentukan secara kodrat $^{3}$ sehingga dapat disebutkan juga bahwa anak memiliki Hak Asasi Manusia sama dengan orang dewasa Hak Asasi Manusia ${ }^{4}$ yang diakui oleh lembaga negara dan juga diakui oleh dunia yangdirumuskan oleh PBB menjadi suatu norma internasional yang hidup antar negara tetapi permasalahan yang tiap tahun ada diberbagi negara khususnya negara Indonesia sulitnya penegakan atas Hak Asasi Manusia (HAM) terhadap anak sehingga masih membutuhkan perhatian khusus dari semua pihak sehingga setiap anak merasa hak nya dilindungi dan mendapat perlakuan yang sama layaknya makhluk hidup. Penegakan hukym pidana harus dilakukan untuk melindungi hak-hak korban. ${ }^{5}$ Upaya penegakan hukum terhadap HAM terhadap anak merupakan salah satu kewajiban Negara terhadap rakyat Indonesia dalam menjamin pelaksanaan hak-hak yang fundamental dalam proses penegakan HAM terhadap anak berlandaskan kepada ideologi negara yaitu pancasila yang mengedepankan nilai-nilai kemanusiaan, menghormati hak asasi setiap warga negara. Dalam berbagai masalah dalam kehidupan masyarakat yang harus menjadi perhatian lebih yakni adanya penegakan Hak asasi manusia terhadap anak menjadi suatu peristiwa yang menyedihkan dan juga prihatin dalam setiap negara khususnya di wilayah indonesia hal demikian telah menimpa seorang anak laki-laki yang dibunuh oleh Ibu kandungnya dijadikan objek kajian Sebagai contoh kasus dalam tulisan ini yang dilansir dari liputan6.com, Pada Minggu tanggal 04 bulan desember tahun 2016

\footnotetext{
${ }^{2}$ https://pih.kemlu.go.id/files/UUNo23tahun2003PERLINDUNGANANAK.pdf diakses 17 Juli 2020

${ }^{3}$ Afriansyah, dkk. (2016) Hak Asasi Manusia dan Perubahan Sosial Politik. (Malang: Badan Penerbit Universitas Muhammadiyah Malang. Hal 12

${ }^{4}$ Harefa Beniharmoni, (2019) Kapita Selekta Perlindungan Hukum Bagi Anak. Yogyakarta: Penerbit Deepublish.

${ }^{5}$ Latukau, F. (2020). Pengadopsian UNCAC Mengenai Pengembalian Aset Hasil Korupsi Yang Dibawa Atau Disimpan Ke Luar Negeri Dalam Penegakan Hukum Indonesia. Jurnal Belo, Volume 5 Nomor 1. DOI: https://doi.org/10.30598/belovol5issue1page10-31
} 
warga Jawa Tengah khususnya wilayah Grobongan dikagetkan dengan peristiwa seorang Ibu membunuh balita laki-laki yang merupakan anak kandungnya menggunakan senjata tajam yang di gunakan untuk menggorok leher sang balita yang kemudian diseret oleh sang ibu usai menggorok leher balita tersebut. ${ }^{6}$

Sebagai contoh kasus lainnya seperti ditayangkan dalam acara televisi Patroli Indosiar, Kamis (18/7/2019) Seorang ibu berusia 30 tahun di Boyolali tega membunuh anak kandungnya berusia 6 tahun karena berdalih impitan ekonomi menjadi faktor penganiayaan yang sudah dilakukan sejak beberapa hari sebelum korban tewas. Demi kepentingan autopsi, makam korban dibongkar. Hasilnya didapati bahwa Fadli tewas akibat benturan benda keras. ${ }^{7}$ Untuk itu penulis tertari membahas Bagaimana perlindungan hak asasi manusia terhadap anak korban tindak pidana menurut hukum?, dan bagaimana peran pemerintah dalam dalam melindungi hak asasi manusia terhadap anak?

Metode yang digunakan penulis dalam penyusunan artikel ilmiah ini adalah penelitian hukum normatif. Penelitian hukum normatif merupakan penggabungan penelitian hukum normatif berfungsi untuk memberikan arguentasi hukum (legal argumentation) dengan mengambil perannya untuk mempertahankan aspek kritis dari keilmuan hukumnya sebagai ilmu normatif yang sui generis). ${ }^{8}$ Metode menganalisis berbagai peraturan perundang-undangan yang berkaitan dengan permasalahan yang dibahas sebagai premis mayor dan fakta-fakta hukum sebagai premis minor untuk selanjutnya ditarik suatu kesimpulan.

${ }^{6}$ https://www.liputan6.com/regional/read/2669411/ibu-tega-hilangkan-nyawa-anak-kandung diakses 18 Agustus 2020

${ }^{7}$ https://www.liputan6.com/news/read/4015585/aniaya-anak-hingga-tewas-ibu-di-boyolaliterancam-15-tahun-penjara diakses 11 Agustus 2020

${ }^{8}$ I Made Pasek Diantha, (2019), Metodologi Penelitian Hukum Normatif Dalam Justifikasi Teori Hukum, Jakarta: Prenadamedia Group, hal.7.

DOI: https://doi.org/10.30598/belovol6issue1page89-100 


\section{Pembahasan}

Perlindungan HAM terhadap anak korban tindak pidana diatur dalas Undangundang sebagai suatu payung hukum bagi kewajiban Negara terhadap rakyat Indonesia dalam menjamin pelaksanaan hak-hak yang fundamental proses perlindungan serta penegakan $\mathrm{HAM}^{9}$ dilakukan dengan berlandaskan kepada ideologi negara yaitu pancasila yang mengedepankan nilai-nilai kemanusiaan, menghormati hak asasi setiap warga negara baik orang dewasa maupun anak-anak ${ }^{10}$ upaya ini membutuhkan jaminan demi kelangsungan perlindungan anak korban tibdak pidana agar bukan saja memunjulkan kepastian hukum, namun juga keadilan bagi anak tersebut. ${ }^{11}$ Menurut hukum hak asasi manusia terhadap anak diatur jelas dalam berbagai aspek antara lain :

\section{a) Menurut Undang-Undang Dasar 1945}

Di dalam ketentuan Pasal 28 B ayat (2) Undang-Undang Dasar 1945 ditegaskan bahwa: "Setiap anak berhak atas kelangsungan hidup, tumbuh dan berkembang serta berhak atas perlindungan dari kekerasan dan diskriminasi“ Hal ini mengandung makna bahwa anak adalah subjek hukum dari hukum nasional yang harus dilindungi, dipelihara dan dibina untuk mencapai kesejahteraan anak. Pengertian anak menurut Irma Setyowati Soemitro, memberikan penjabaran bahwa "Ketentuan Undang-Undang Dasar 1945, ditegaskan pengaturannya dengan dikeluarkannya Undang-Undang Nomor 4 Tahun 1979 tentang Kejahteraan Anak yang berarti makna anak yaitu seorang anak yang harus memperoleh hak-hak yang kemudian hak-hak tersebut dapat menjamin pertumbuhan dan perkembangannya dengan dengan wajar, baik secara lahiriah, jasmani mapun sosialnya. Anak juga berhak atas pemeliharaan

${ }^{9}$ Putra, Muhammad Amin. (2015) "Eksistensi Lembaga Negara Dalam Penegakan HAM Di Indonesia". Fiat Justisia. Jurnal Ilmu Hukum. 9, (3) Hal 12-20

${ }^{10}$ Subi Moh. (2017), Implementasi Hak Asasi Manusia dalam Undang-Undang Dasar 1945.Jakarta:Rasi Penerbit.

${ }^{11}$ Zein Fadhilah, (2017), Anak dan Keluarga Dalam Teknologi Informasi. Jakarta: Perpustaan Nasional. Hal 12

DOI: https://doi.org/10.30598/belovol6issue1page89-100 
dan perlindungan baik semasa dalam kandunga maupun sesudah ia dilahirkan." 12

\section{b) Menurut Undang-Undang Nomor 4 Tahun 1979 Tentang Kesejahteraan Anak}

Anak merupakan karunia dan amanah Allah SWT yang senantiasa dijaga dan dilindungi ${ }^{13}$ maka itu hak anak atas kesejahteraan diatur dalam Bab II Undang-Undang Nomor 4 Tahun 1979, hak-hak tersebut antara lain:

1) Hak atas kesejahteraan, perawatan, asuhan, dan bimbingan.

2) Hak atas pelayanan.

3) Hak atas pemeliharaan dan perlindungan.

4) Hak atas perlindungan lingkungan hidup.

5) Hak mendapatkan pertolongan pertama.

6) Hak memperoleh asuhan.

7) Hak memperoleh bantuan.

8) Hak memperoleh pelayanan khusus.

Akan tetapi hal seperti ini serikali diabaikan oleh orangtua yang sering beranggapan bahwa seorang anak menjadi anak kandungnya sehingga orang tua bebas memperlakukan anak sesuai keinginannya. ${ }^{14}$

c) Menurut Undang-Undang Nomor 39 Tahun 1999 Tentang Hak Asasi Manusia Undang-Undang Nomor 39 Tahun 1999 Tentang Hak Asasi

Manusia Pasal 52 ayat (1) ditegaskan bahwa: "Hak melindungi sejak dari dalam kandungan" dan pada Pasal 58 ayat (1) ditegaskan bahwa: "Hak perlindungan hukum" memberikan jaminan kepada setiap anak untuk mendapatkan perlindungan hukum dari segala bentuk kekerasan fisik atau mental, penelantaran, perlakuan buruk, dan pelecehan seksual selama dalam pengasuhan orang tua atau walinya, atau pihak lain yang bertanggung jawab.

\footnotetext{
${ }^{12}$ Ibid. hal 56

${ }^{13}$ Chandra Mardi, (2018)Aspek perlindungan anak Indonesia. Jakarta: Penerbit Kencana. hal 27

${ }^{14}$ Patty, J. (2020). Tindak Kekerasan Terhadap Anak di Lingkungan Satuan Pendidikan dan Peranan Keluarga Sebagai Upaya Non-Penal Dalam Pencegahan. Jurnal Belo, 5(2), 115-129. DOI : https://doi.org/10.30598/belovol5issue2page115-129
}

DOI: https://doi.org/10.30598/belovol6issuelpage89-100 
Pengertian tersebut juga berarti hak yang ada pada setiap manusia merupakan pemberian Tuhan ${ }^{15}$ yang meliputi Hak Asasi Anak Menurut Undang-Undang Nomor 39 Tahun 1999 meliputi:

1) Anak mendapat perlindungan orang tua, masyarakat dan negara (Pasal 62 ayat (1))

2) Hak melindungi sejak dari dalam kandungan (Pasal 52 ayat (1))

3) Hak hidup dan meningkatkan taraf kehidupan (Pasal 53 ayat (1))

4) Hak mendapat nama dan status kewarganegaraan (Pasal 53 ayat (2))

5) Hak mendapat perawatan, pendidikan, pelatihan dan bantuan khusus anak cacat fisik atau mental (Pasal 54)

6) Hak untuk beribadah menurut agamanya, berpikir dan berekspresi (Pasal $55)$

7) Hak mengetahui, dibesarkan dan diketahui orang tuanya ((Pasal 56 ayat (1))

8) Hak diasuh dan diangkat anak oleh orang lain ((Pasal 56 ayat (2))

9) Hak dibesarkan, dipelihara, dirawat, dididik, diarahkan dan dibimbing orang tua/wali ((Pasal 57 ayat (1))

10) Hak mendapatkan orang tua angkat atau wali ((Pasal 57 ayat (2))

11) Hak perlindungan hukum ((Pasal 58 ayat (1) ${ }^{16}$

\section{d) Menurut Undang-Undang Nomor 23 Tahun 2002 Tentang Perlindungan Anak}

Dalam proses tumbuh kembang anak membutuhkan perlindungan rasa aman dari orangtua, ${ }^{17}$ dalam kehidupan berbangsa dan bernegara anak adalah masa depan bangsa dan generasi penerus cita-cita bangsa sehingga setiap anak berhak atas kelangsungan hidup, tumbuh kembang, berpartisipasi serta berhak

\footnotetext{
${ }^{15}$ Sabon Boli, Hak Asasi Manusia bahan pendidikan untuk perguruan tinggi, (Jakarta: Universitas Atma Jaya,2019)

16 Fadillah, A. (2019). Perlindungan Hukum Terhadap Anak Yang Menjadi Korban Aksi Perundungan. Jurnal Belo, 5(1), 86-100. DOI: https://doi.org/10.30598/belovol5issuelpage86-100

${ }^{17}$ Prasetyo Herry, (2019)Agar anak merasa dicintai. Jakarta: Penerbit Duta. Hal. 21
}

DOI: https://doi.org/10.30598/belovol6issuelpage89-100 
atas perlindungan dari tindak kekerasan dan diskriminasi serta hak sipil dan kebebasan. Pasal 17 Undang-Undang Nomor 23 Tahun 2002 tentang Perlindungan Anak menyebutkan bahwa: ${ }^{18}$

1) Setiap anak yang dirampas kebebasannya berhak untuk mendapatkan perlakuan secara manusiawi dan penempatannya dipisahkan dari orang dewasa, memperoleh bantuan hukum atau bantan lainnya secara efektif dalam setiap tahapan upaya yang berlaku, membela diri dan memperoleh keadilan di depan pengadilan anak yang objektif dan tidak memihak dalam sidang tertutup untuk umum.

2) Setiap anak yang menjadi korban atau pelaku kekerasan seksual atau yang berhadapan dengan korban hukum berhak dirahasiakan.

3) Negara Kesatuan Republik Indonesia menjamin kesejahteraan tiap-tiap warga negaranya termasuk perlindungan terhadap hak-hak anak yang merupakan hak asasi manusia yang dalam dirinya melekat harkat dan martabat sebagai manusia seutuhnya. ${ }^{19}$

4) Peran pemerintah dalam memperhatikan hak asasi manusia yang melekat pada anak dari tahun ke tahun mulai signifikan dalam mengatasi berbagai masalah terutama dalam penangganan anak sebagai korban dalam berbagai peristiwa dengan berlalunya berbagai Undang-Undang yang melindungi hak anak. Namun perlu maksimalkan upaya penegakan hak asasi manusia terhadap anak dengan memberikan sosialisasi pelibatan dan peran penting masyarakat dalam melindungi anak dilakukan secara tidak berkesinambungan.

${ }^{18}$ Lokollo, L., Salamor, Y. B., \& Ubwarin, E. (2020). Kebijakan Formulasi Undang-undang Narkotika Dalam Legalisasi Penggunaan Ganja Sebagai BahanPengobatan di Indonesia. Jurnal Belo, Volume 5 Nomor 2. DOI: https://doi.org/10.30598/belovol5issue2page1-20

${ }^{19}$ Arliman, Laurensius. (2017)“Komnas Hak Asasi Manusia sebagai State Auxialiary Bodies Di Dalam Penegakan Hak Asasi Manusia di Indonesia”. Jakarta: Komnas Ham. Hal 19 


\section{Penutup}

Kesimpulan

Hak-hak dasar yang dimiliki oleh manusia yang melekat pada hakikat dan keberadaan manusia sebagai makhluk Tuhan Yang Maha Esa dan merupakan anugerahNya yang wajib dihormati, dijunjung tinggi dan dilindungi oleh negara, hukum dan Pemerintah. Setiap individu mempunyai keinginan agar HAM-nya terpenuhi, tapi satu hal yang perlu kita ingat bahwa jangan pernah melanggar atau menindas HAM orang lain. Dalam kehidupan bernegara ham diatur dan dilindungi oleh peraturan perundangundangan negara republik indonesia. Jika dimana seseorang atau sekelompok dan bahkan instansi yang melakukan pelanggaran ham akan diadili dalam peradilan HAM sebagaimana diatur dalam peraturan perundang-undangan. Bentuk perlindungan ham terhadap anak korban tindak pidana sudah diatur dalam konvensi hak-hak anak yang dimana hak - hak anak harus dilindungi dan dijamin agar dapat hidup, tumbuh, kembang dan berprestasi di dalam mendapatkan pendidikan yang layak dan bermutu. Dalam penegakan ham terhadap anak telah berjalan kelembagaan dan peraturan perundangundangan yang dapat menjamin pelaksanaannya dalam menegakan perlindungan hak hak asasi manusia. Upaya perlindungan dan penegakan hukum terhadap HAM merupakan salah satu kewajiban Negara terhadap rakyat Indonesia dalam menjamin pelaksanaan hak-hak yang fundamental proses penegakan HAM dilakukan dengan berlandaskan kepada ideologi negara yaitu pancasila yang mengedepankan nilai-nilai kemanusiaan, menghormati hak asasi setiap warga negara. 
Saran

Setiap manusia harus menyadari bahwa Hak Asasi Manusia merupakan hak yang tidak dapat di ganggu gugat, maka oleh karena itu kita harus mampu mempertahankan dan memperjuangkan HAM kita sendiri, namun tidak boleh bertentangan dengan Hakhak orang lain dan tidak boleh bertentangan dengan peraturan perundang-undangan. Selain itu, kita juga harus menghormati dan menjaga HAM orang lain terutama anakanak dan jangan sampai kita melakukan pelanggaran HAM kita harus mempunyai kesadaran bahwa kita harus menjaga dan menghormati hak-hak orang lain. Kami juga menghimbau bagi para orang tua karena sangat berperan penting dalam melindungi hakhak terhadap anak untuk dapat hidup, tumbuh, berkembang, member perlindungan dan berpartisipasi dan Pemerintah para penegak hukum ataupun instansi-instansi yang berwenang dapat melaksanakan kewajibannya untuk melindungi hak-hak seseorang ataupun hak - hak anak agar tidak terus terjadi pelanggaran HAM. Kondisi HAM di Indonesia sudah saatnya dibenahi dan ditata ulang agar terbentuk good goverment segala jenis hambatan dan tantangan yang dapat mengganggu terwujudnya pelaksanaan HAM harus segera dihilangkan.

\section{Daftar Pustaka}

\section{Jurnal}

[1] Fadillah, A. (2019). Perlindungan Hukum Terhadap Anak Yang Menjadi Korban Aksi Perundungan. Jurnal Belo, 5(1), 86-100. DOI: https://doi.org/10.30598/belovol5issue1page86-100

[2] Patty, J. (2020). Tindak Kekerasan Terhadap Anak di Lingkungan Satuan Pendidikan dan Peranan Keluarga Sebagai Upaya Non-Penal Dalam Pencegahan. Jurnal Belo, 5(2), 115-129. $\quad$ DOI : https://doi.org/10.30598/belovol5issue2page115-129 
[3] Latukau, F. (2020). Pengadopsian UNCAC Mengenai Pengembalian Aset Hasil Korupsi Yang Dibawa Atau Disimpan Ke Luar Negeri Dalam Penegakan Hukum Indonesia. Jurnal Belo, Volume 5 Nomor 1. DOI: https://doi.org/10.30598/belovol5issue1page10-31

[4] Lokollo, L., Salamor, Y. B., \& Ubwarin, E. (2020). Kebijakan Formulasi Undang-undang Narkotika Dalam Legalisasi Penggunaan Ganja Sebagai BahanPengobatan di Indonesia. Jurnal Belo, Volume 5 Nomor 2. DOI: https://doi.org/10.30598/belovol5issue2page1-20

[5] Putra, Muhammad Amin. (2015) "Eksistensi Lembaga Negara Dalam Penegakan HAM Di Indonesia". Fiat Justisia. Jurnal Ilmu Hukum. 9 (3). DOI : https://doi.org/10.25041/fiatjustisia.v9no3.600

\section{Buku}

[6] E Gunakaya,Widiada. (2017)Hukum Hak Asasi Manusia. Yogyakarta: Andi Jogja

[7] Afriansyah, dkk. (2016) Hak Asasi Manusia dan Perubahan Sosial Politik. Malang:Badan Penerbit Universitas Muhammadiyah Malang.

[8] I Made Pasek Diantha, (2019), Metodologi Penelitian Hukum Normatif Dalam Justifikasi Teori Hukum, Jakarta: Prenadamedia Group.

[9] Subi Moh. (2017), Implementasi Hak Asasi Manusia dalam Undang-Undang Dasar 1945.Jakarta:Rasi Penerbit.

[10] Zein Fadhilah, (2017), Anak dan Keluarga Dalam Teknologi Informasi. Jakarta: Perpustaan Nasional.

[11] Chandra Mardi, (2018), Aspek perlindungan anak Indonesia. Jakarta: Penerbit Kencana 
[12] Sabon Boli, (2019) Hak Asasi Manusia bahan pendidikan untuk perguruan tinggi, Jakarta: Universitas Atma Jaya,

[13] Prasetyo Herry, (2019)Agar anak merasa dicintai. Jakarta: Penerbit Duta.

[14] Arliman, Laurensius. (2017)“Komnas Hak Asasi Manusia sebagai State Auxialiary Bodies Di Dalam Penegakan Hak Asasi Manusia di Indonesia”. Jakarta: Komnas Ham.

[15] Harefa Beniharmoni, (2019) Kapita Selekta Perlindungan Hukum Bagi Anak. Yogyakarta: Penerbit Deepublish.

\section{Lain-lian}

[16] https://pih.kemlu.go.id/files/UUNo23tahun2003PERLINDUNGANANAK.pdf diakses 17 Juli 2020

[17] https://www.liputan6.com/regional/read/2669411/ibu-tega-hilangkan-nyawaanak-kandung diakses 18 Agustus 2020

[18] https://www.liputan6.com/news/read/4015585/aniaya-anak-hingga-tewas-ibu-diboyolali-terancam-15-tahun-penjara diakses 11 Agustus 2020 